\title{
The Loss of Smell and Taste in the COVID-19 Outbreak: a Tale of Many Countries
}

\author{
Joaquim Mullol ${ }^{1,2,3} \cdot$ Isam Alobid ${ }^{1,2,3}$ • Franklin Mariño-Sánchez ${ }^{4}$. Adriana Izquierdo-Domínguez ${ }^{5}$. \\ Concepció Marin ${ }^{2,3} \cdot$ Ludger Klimek $^{6} \cdot$ De-Yun Wang $^{7} \cdot$ Zheng Liu $^{8}$
}

Published online: 3 August 2020

(C) Springer Science+Business Media, LLC, part of Springer Nature 2020

\begin{abstract}
Purpose of Review Olfactory dysfunction in upper airway viral infections (common cold, acute rhinosinusitis) is common (> $60 \%$ ). During the COVID-19 outbreak, frequency of sensory disorders (smell and/or taste) in affected patients has shown a high variability from 5 to $98 \%$, depending on the methodology, country, and study.

Recent Findings A sudden, severe, isolated loss of smell and/or taste, in the absence of other upper airway inflammatory diseases (allergic rhinitis, chronic rhinosinusitis, nasal polyposis), should alert individuals and physicians on being potentially affected by COVID-19. The evaluation of smell/taste disorders with a visual analogue scale or an individual olfactory or gustatory test, at the hospital or by telemedicine, to prevent contamination might facilitate an early detection of infected patients and reduce the transmission of SARS-CoV-2.

Summary During the COVID-19 outbreak, patients with sudden loss of smell should initiate social distancing and home isolation measures and be tested for SARS-CoV-2 diagnostic test when available. Olfactory training is recommended when smell does not come back after 1 month but can be started earlier.
\end{abstract}

Keywords Smell and taste dysfunction $\cdot$ Acute rhinosinusitis $\cdot$ Hyposmia $\cdot$ Anosmia $\cdot$ SARS-CoV-2 $\cdot$ COVID-19

\section{Introduction: When and Where Did Everything Start?}

In the past 20 years, mankind has experienced two severe coronavirus infections, the severe acute respiratory syndrome (SARS) outbreak in 2002 and the Middle East respiratory syndrome (MERS) in 2012. The first cases of the COVID-19 outbreak started in December 2019 in Wuhan (China) in patients with complicated pneumonia [1]. The disease is caused by a new coronavirus (SARS-CoV-2) from a potential bat origin [2]

Joaquim Mullol

jmullol@clinic.cat

$1 \quad$ Rhinology Unit \& Smell Clinic, ENT Department, Hospital Clinic Barcelona, Barcelona, Catalonia, Spain

2 INGENIO, Clinical \& Experimental Respiratory Immunoallergy, IDIBAPS, Barcelona, Catalonia, Spain

3 CIBER of Respiratory Diseases (CIBERES), Barcelona, Catalonia, Spain and from which viral genome was rapidly characterized [3]. In January 2020, angiotensin-converting enzyme 2 (ACE2) was identified as the functional receptor for SARS-CoV-2, present in multiple human organs including the central nervous system.

The disease progressively spread to other Asian countries, Iran, and European countries such as Italy, Spain, France, Germany, and UK. Later the COVID-19 also spread to African and North and South American countries such as USA, Mexico, Brazil, and Argentina. Until the present day ( early August 2020), COVID-19 has affected 188 countries,

$4 \quad$ Rhinology and Skull Base Surgery Unit, ENT Department, Hospital Universitario Ramón y Cajal, Madrid, Spain

5 Department of Allergy, Consorci Sanitari de Terrassa, Barcelona, Catalonia, Spain

6 Center for Rhinology and Allergology, Wiesbaden, Germany

7 Department of Otolaryngology, Yong Loo Lin School of Medicine, National University of Singapore, Singapore, Singapore

8 Department of Otolaryngology-Head and Neck Surgery, Tongji Hospital, Tongji Medical College, Huazhong University of Science and Technology, Wuhan, People's Republic of China 
infected over 18 million people (probably a larger number if infected people who did not undergo a proper diagnostic test are considered), and caused more than 700,000 deaths all over the World. The WHO declared the disease a global pandemic on March 11, 2020.

The common symptoms of COVID-19 are general malaise, fever, cough, and shortness of breath. Other symptoms include muscle and joint pain, sore throat, headache, nausea or vomiting, diarrhea, and some nasal symptoms, especially smell and taste dysfunction. Similar to other upper airway viral infections (URTI), such as common cold or flu, the loss of smell is a frequent symptom in COVID-19 patients. However, a sudden, severe, and isolated loss of smell and/or taste may also be present in COVID-19 patients who are otherwise asymptomatic.

\section{How Smell Works and How Common Is Its Dysfunction?}

Nasal airflow odorants reach the olfactory neuro-epithelium which covers a surface of $8-10 \mathrm{~cm}^{2}$ of the olfactory cleft in the upper part of the nasal cavities and they where bind/activate olfactory receptor (OR) proteins. The olfactory neuroepithelium contains 5-30 million receptor neurons which express up to 350 different OR [4]. On the other hand, the sense of taste is conveyed through only 5 taste receptors (sweet, salted, bitter, acidic/sour, umami/sodium glutamate) expressed in the tongue and palate gustatory buds.

The OLFACAT (OLFAction in CATalonia) survey reported a prevalence of loss of smell, either partial (hyposmia, 1 out of 5) or total (anosmia, 1 out of 300), of almost $20 \%$ of the European general population (82 million of EU citizens) [5]. A recent epidemiological study reported a prevalence of $13.5 \%$ for smell impairment, $17.3 \%$ for taste impairment, and $2.2 \%$ for both taste and smell impairment in the US adult population [6]. Smell dysfunction has a significant impact on quality of life (QoL) as well as decreased abiliyty to detect noxious environmental elements such as fires, gas leaks, spoilded food, a reduction in appetite and eventually malnutrition, immunity reduction, and worsening of medical illness. Loss of smell has been also associated with increased mortality.

\section{Why Does Loss of Smell Occur?}

Major causes of acquired smell loss include URTI by respiratory viruses (adenovirus, rhinovirus, coronavirus, influenza), traumatic brain injury, upper airway inflammation (rhinitis, rhinosinusitis), and neurodegenerative (Parkinson and Alzheimer) diseases while minor causes are intracranial/ sinonasal tumors, drugs, exposure to toxic substances, irradiation, or iatrogenic factors [7].
Loss of smell is a common $(>60 \%)$ and usually transient (3-7 days) symptom in common cold and acute rhinosinusitis [8], with the post-viral etiology being also the most frequent cause of permanent loss of smell. The loss of taste has not been, however, thoroughly investigated in URTI. Smell loss in URTI is caused by a multifactorial combination of mechanical obstruction for the odorant transmission in the olfactory cleft due to mucosal inflammation (cytokine storm) and shedding (neurodegeneration) of the olfactory neuro-epithelium which interfere with odorants binding to OR [9]. ACE2 and TMPRSS2, two protein receptors which are required for host cell entry and facilitate accumulation, replication, and binding of SARS-CoV-2, are expressed in the sustentacular cells and, in a lower extent, in the OR neurons of the olfactory neuroepithelium, having a potential role for the loss of smell in COVID-19 patients [10].

\section{How Can Loss of Smell Be Measured in COVID-19?}

In COVID-19 patients, smell and taste assessment may be performed by (a) written or online questionnaires, these being qualitative but most of them lacking quantitative assessment; (b) a visual analogue scale (VAS, $0-10 \mathrm{~cm}$ ), this being a fast, easy to perform, and safe quantitative method to be used in daily clinical practice; or (c) a subjective olfactometry, which is not recommended to be used in a face-to-face application in COVID-19 patients due to the risk of transmission to patients and health professionals [4]. With appropriate training, some of these tests can be performed using video consultations via telemedicine, this being safe for both patient and examiner [11]. Individual tests for smell identification such as UPSIT could be considered safe but, being culturally dependent, they should be properly validated in the different country populations [12]. Chemical gustometry is a useful test to differentiate between flavor (smell in addition to taste) and pure taste disorders but, like for smell tests and due to the high risk of disease transmission, only individual disposable kits are recommended in COVID-19.

\section{Loss of Smell in COVID-19: What Evidence Do We Have?}

On March 2020, the first alarm arose from scientific societies in different countries (UK, USA, Italy, France, or Spain) due to a series of sporadic cases, predominantly in health workers, reporting sudden, severe, and sometimes isolated loss of smell and/or taste [13]. After an initial analysis of the 56 first studies published to date on COVID-19, the Oxford COVID-19 Evidence Service provided a document stating that "the current evidence (grade D) to suggest changes in olfactory sensation is a feature of COVID-19 is limited and inconclusive." 
Since then, a number of prospective and retrospective studies on loss of smell and/or taste in patients with COVID-19 were immediately started and published. In Wuhan, China, Mao et al. [14] reported a retrospective study based on clinical record with a 5\% incidence of loss of smell or taste in 214 hospitalized patients. A survey $(N=3191)$ conducted in Daegu (South Korea) reported an incidence of $12 \%$ of loss of smell or taste. In Milan (Italy), Giacomelli et al. [15] studied 59 hospitalized patients with a $34 \%$ incidence of loss of smell or taste. Lechien et al. [16] reported a high incidence of loss of smell $(86 \%)$ or taste (89\%) in patients with mild-moderate COVID-19, with a significant impact on patient's quality of life, from 4 European countries (France, Belgium, Italy, and Spain).

From March to June 2020, a number of studies on the incidence/frequency of loss of smell (and also taste) have been conducted in many countries and continents (Asia, Europe, America) [17]. A great variability has been found (from 5 to 95\%) however in the incidence of loss of smell (Fig. 1) that probably depends on the methodology of questionnaires and the lack of quantitative assessment. A meta-analysis has recently been published on these COVID-19 loss of smell and/or taste studies [18]. In addition to incidence, most of the studies demonstrated that the majority (>90\%) of COVID-19 patients recover their loss of smell or taste 2 weeks after onset of the sensory dysfunction. In most studies, the loss of taste occurs with a similar incidence than loss of smell that casts doubt on the difference between loss of flavor (smell plus taste) and loss of real taste (only valid for sweet, salty, bitter, and sour/acidic) perceptions. Among the few studies that have clearly differentiated between the loss of smell and taste [19, 20], Song et al. [19] found that loss of taste was more frequent (21\%) than loss of smell $(11 \%)$ in hospitalized patients, the loss of taste but not of smell being associated with severe COVID-19.

A study carried out in Spain (846 COVID-19 patients and 143 controls) did perform a quantitative evaluation of the loss of smell and taste by using a VAS $(0-10 \mathrm{~cm})$ [20]. In addition to $18-19 \%$ of patients having loss of smell and/or taste as the first symptom, this study has found a clear association of loss of smell and taste with younger $(<60$ years old) and nonhospitalized patients. Until June 2020, only one study [21], carried out in $\operatorname{Iran}(N=60)$ reporting the highest incidence of loss of smell (98\%) in COVID-19 patients, has used a smell test (UPSIT) although their results may be doubtful given the lack of validation of that smell test in Iran [12].

\section{Loss of Smell Due to COVID-19, Can We Improve It?}

General preventive measures of hand washing and general hygiene (mask wearing), social distancing, preventive home isolation, and diagnostic tests, when possible, are the first and most important measures to avoid the spread of COVID-19 [22]. Chinese [23] and British [24] investigators have recently developed two vaccines against SARS-CoV-2 virus which have promising future in terms of safety, tolerability, and immunogenicity.

Post-viral loss of smell is the most common cause of permanent olfactory loss and several treatments have been recommended in the literature. Overall, there is no real evidence for any specific pharmacological option for post-viral loss of
Fig. 1 High variability in the frequency/incidence of loss of smell (from 5 to 98\%) in studies and surveys conducted across different countries from Asian, European, and American regions during the COVID-19 outbreak. Study first authors and corresponding countries are displayed in the $Y$ axe legend. In international studies: single asterisk indicates studies/surveys were performed in France, Belgium, Italy, and Spain; double asterisks indicate studies/surveys were performed in the USA, Mexico, Italy, and UK; triple asterisks indicate studies/surveys were performed in France, Belgium, Italy, Spain, and Switzerland
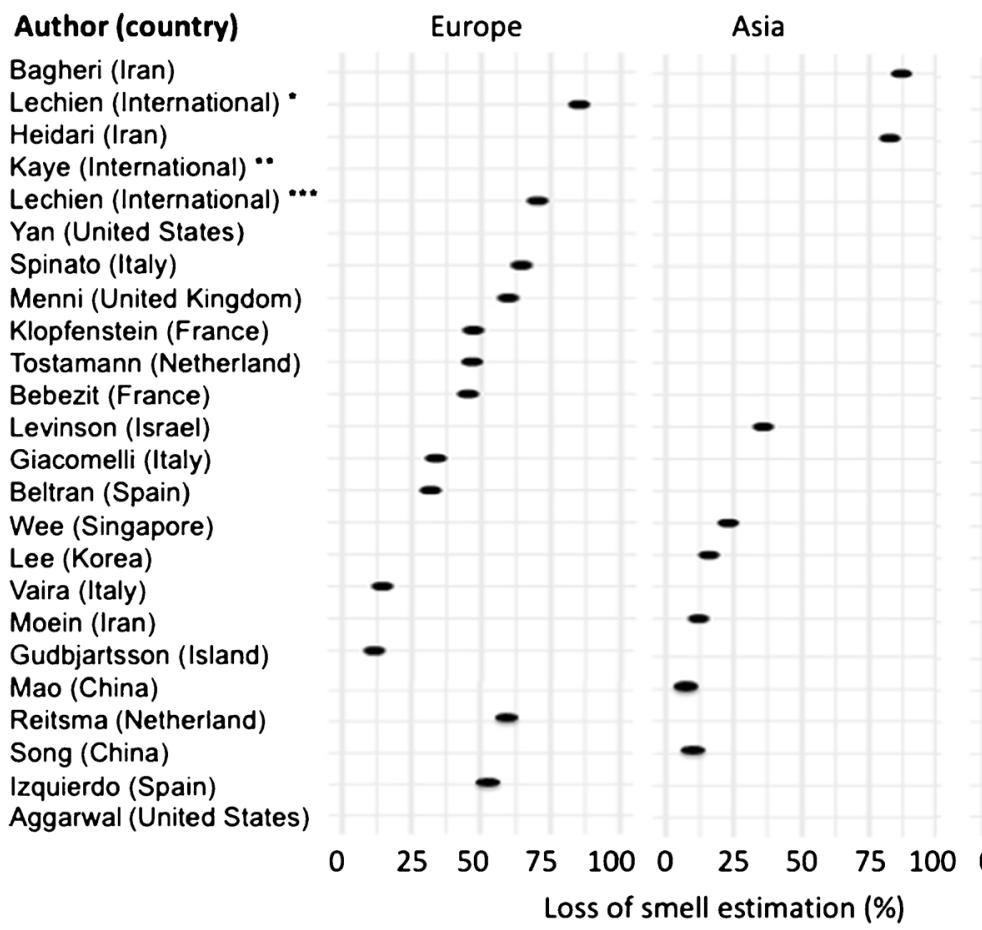

Asia

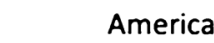

America

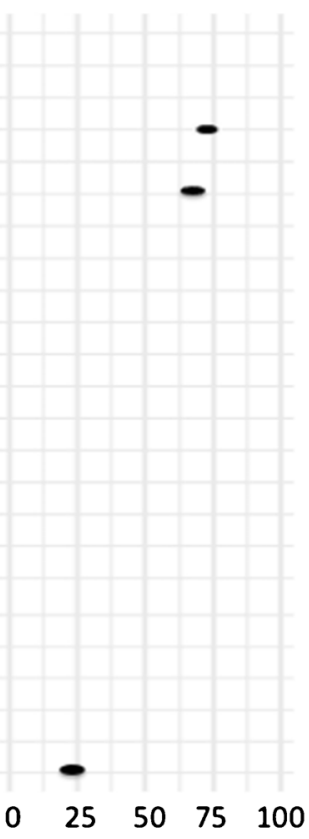

Loss of smell estimation (\%) 
smell [7], including COVID-19. The benefit of corticosteroids, intranasal and/or systemic, on post-viral olfactory loss is not clear although they are often used as first-line therapy to treat more a potential virus exacerbation of CRS than the postviral condition itself. In the COVID-19 outbreak, if patients are being treated with corticosteroids for a sinonasal inflammatory disease (allergic rhinitis or CRS), discontinuation of treatment is not recommended [25].

Olfactory training is the only current evidence-based therapeutic option for post-viral olfactory loss [7]. Over $90 \%$ of COVID-19 patients with loss of smell may recover that sense within the first month, and olfactory training is strongly recommended if smell has not recovered after that period of time but can be started earlier.

\section{What Are the Take-home Messages to?}

- Smell impairment is frequent $(>60 \%)$ in viral (common cold) and post-viral infections and could often (1 out of 5 patients) present as an early sudden, severe, and isolated symptom in COVID-19.

- There is a wide variation on the incidence of smell and/or taste disorders, from 5 to $98 \%$, depending on the specific methodology, country, or study.

- The use of either VAS or/and disposable olfactory or gustatory test is recommended for an appropriate and safe quantitative assessment of the loss of smell or/and taste during COVID-19.

- During the COVID-19 pandemic, general safety measures such as wearing masks, social distancing, and home isolation should be followed. A diagnostic test for SARS-CoV-2 is recommended, when available, for all individuals with sudden, severe, and isolated loss of smell and/or taste.

- Olfactory training should be recommended in COVID-19 patients who experience loss of smell have not yet recovered, this being strongly recommended after 1 month of the dysfunction onset.

\section{Compliance with Ethical Standards}

Conflict of Interest The authors declare no conflicts of interest relevant to this manuscript.

Human and Animal Rights and Informed Consent This article does not contain any studies with human or animal subjects performed by any of the authors.

\section{References}

1. Zhu N, Zhang D, Wang W, Li X, Yang B, Song J, et al. A novel coronavirus from patients with pneumonia in China, 2019. N Engl J Med. 2020;382:727-33.
2. Zhou P, Yang XL, Wang XG, Hu B, Zhang L, Zhang W, et al. A pneumonia outbreak associated with a new coronavirus of probable bat origin. Nature. 2020;579(7798):270-3.

3. Lu R, Zhao X, Li J, Niu P, Yang B, Wu H, et al. Genomic characterization and epidemiology of 2019 novel coronavirus: implications for virus origins and receptor binding. Lancet. 2020;395(10224):565-74.

4. Mullol J, Mariño-Sánchez F, Valls M, Alobid I, Marin C. The sense of smell in chronic rhinosinusitis. J Allergy Clin Immunol. 2020;145:773-6.

5. Mullol J, Alobid I, Mariño-Sánchez F, Quintó L, de Haro J, BernalSprekelsen M, et al. Furthering the understanding of olfaction, prevalence of loss of smell and risk factors: a population-based survey (OLFACAT study). BMJ Open. 2012;2:e001256.

6. Liu G, Zong G, Doty RL, Sun Q. Prevalence and risk factors of taste and smell impairment in a nationwide representative sample of the US population: a cross-sectional study. BMJ Open. 2016;6(11): e013246.

7. Hummel T, Whitcroft KL, Andrews P, Altundag A, Cinghi C, Costanzo RM, et al. Position paper on olfactory dysfunction. Rhinol Suppl. 2017;54:1-30.

8. Jaume F, Quintó L, Alobid I, Mullol J. Overuse of diagnostic tools and medications in acute rhinosinusitis in Spain: a population-based study (the PROSINUS study). BMJ Open. 2018;8(1):e018788.

9. Butowt R, Bilinska K. SARS-CoV-2: olfaction, brain infection, and the urgent need for clinical samples allowing earlier virus detection. ACS Chem Neurosci. 2020;11(9):1200-3.

10. Bilinska K, Jakubowska P, Von Bartheld CS, Butowt R. Expression of the SARS-CoV-2 entry proteins, ACE2 and TMPRSS2, in cells of the olfactory epithelium: identification of cell types and trends with age. ACS Chem Neurosci. 2020;11(11):155-62.

11. Klimek L, Hagemann J, Alali A, Spielhaupter M, Hupperts T, Hörmann K, et al. Telemedicine allows quantitative measuring of olfactory dysfunction in COVID-19. Allergy. 2020. https://doi.org/ 10.1111/all.14467.

12. Mariño-Sánchez F, Santamaría A, de los Santos G, Alobid I, Mullol J. Psychophysical olfactory testing in COVID-19: is smell function really impaired in nearly all patients? Int Forum Allergy Rhinol. 2020. https://doi.org/10.1002/alr.22639.

13. Lechner M, Chandrasekharan D, Jumani K, Liu J, Gane S, Lund $\mathrm{VJ}$, et al. Anosmia as a presenting symptom of SARS-CoV-2 infection in healthcare workers - a systematic review of the literature, case series, and recommendations for clinical assessment and management. Rhinology. 2020. https://doi.org/10.4193/Rhin20.189.

14. Mao L, Jin H, Wang M, Hu Y, Chen S, He Q, et al. Neurologic manifestations of hospitalized patients with coronavirus disease 2019 in Wuhan, China. JAMA Neurol. 2020;77(6):1-9.

15. Giacomelli A, Pezzati L, Conti F, Bernacchia D, Siano M, Oreni L, et al. Self-reported olfactory and taste disorders in SARS-CoV-2 patients: a cross-sectional study. Clin Infect Dis. 2020;71(15):88990.

16. Lechien JR, Chiesa-Estomba CM, De Siati DR, Horoi M, Le Bon $\mathrm{SD}$, Rodriguez A, et al. Olfactory and gustatory dysfunctions as a clinical presentation of mild-to-moderate forms of the coronavirus disease (COVID-19): a multicenter European study. Eur Arch Otorhinolaryngol. 2020;277(8):2251-61.

17. Izquierdo-Domínguez A, Rojas-Lechuga MJ, Mullol J, Alobid I. Olfactory dysfunction in the COVID-19 outbreak. J Investig Allergol Clin Immunol. 2020. https://doi.org/10.18176/jiaci.0567.

18. Tong JY, Wong A, Zhu D, Fastenberg JH, Tham T. The prevalence of olfactory and gustatory dysfunction in COVID-19 patients: a systematic review and meta-analysis. Otolaryngol Head Neck Surg. 2020;163(1):3-11.

19. Song J, Deng YK, Wang H, Wang ZC, Liao B, Ma J, et al. Selfreported taste and smell disorders in patients with COVID-19: 
distinct features in China. Asian J Clin Exp Otolaryngol. 2020. https://doi.org/10.1101/2020.06.12.20128298.

20. Izquierdo-Domínguez A, Rojas-Lechuga MJ, Chiesa-Estomba C, Calvo-Henríquez C, Ninchritz-Becerra E, Soriano-Reixach M, et al. Smell and taste dysfunctions in COVID-19 are associated with younger age in ambulatory settings - a multicenter cross-sectional study. J Investig Allergol Clin Immunol. 2020. https://doi.org/10. 18176/jiaci.0595.

21. Moein ST, Hashemian SMR, Mansourafshar B, Khorram-Tousi A, Tabarsi P, Doty RL. Smell dysfunction: a biomarker for COVID19. Int Forum Allergy Rhinol. 2020;10(8):944-50.

22. Pfaar O, Klimek L, Jutel M, Akdis C, Bousquet J, Breiteneder H, et al. COVID-19 pandemic: practical considerations on the organization of an allergic clinic - an EAACI/ARIA position paper. Allergy. 2020. https://doi.org/10.1111/all.14453.

23. Zhu FC, Li YH, Guan XH, Hou LH, Wang WJ, Li J-X, et al. Safety, tolerability, and immunogenicity of a recombinant adenovirus type-
5 vectored COVID-19 vaccine: a dose-escalation, open-label, nonrandomised, first-in-human trial. Lancet. 2020;395(10240):184554.

24. Folegatti PM, Ewer KJ, Aley PK, Angus B, Becker S, Sandra BelijRammerstorfer S, et al. Safety and immunogenicity of the ChAdOx1 nCoV-19 vaccine against SARS-CoV-2: a preliminary report of a phase 1/2, single-blind, randomised controlled trial. Lancet. 2020.

25. Bousquet J, Akdis C, Jutel M, Bachert C, Klimek L, Agache I, et al. Intranasal corticosteroids in allergic rhinitis in COVID-19 infected patients: an ARIA-EAACI statement. Allergy. 2020. https://doi. org/10.1111/all.14302.

Publisher's Note Springer Nature remains neutral with regard to jurisdictional claims in published maps and institutional affiliations. 